\section{National Laboratory Futures}

Many European nations have established national laboratories. Most of these laboratories were set up for specific missions, ranging from nuclear energy to testing the adulteration of tobacco. Many such laboratories achieved justified reputations for excellence and for the range and depth of their technical capabilities. Most contributed to their country's technical workforces, not just through scientists experienced in large interdisciplinary projects, but also through skilled technicians who made possible the success of some of the small innovative high-technology firms.

In a few nations, not just in Europe, the futures of these laboratories are being questioned. Governments have amalgamated, downsized or privatized laboratories, sometimes successfully. Industries have followed this fashion, and have done the same with their central laboratories. In the UK, this questioning has become a habit. Yet again, the futures of the Public
Sector Research Establishments (PSRE) are "under review." The value of these exercises can be doubted. These doubts have been given substantial support in the Royal Society's published submission to the UK House of Commons Select Committee Inquiry on the so-called Prior Options exercise.

The Royal Society, (the UK's premier scientific academy) makes four telling points. First, the UK government has failed to provide evidence for the assumptions underpinning the review. True, there are some arguments given about where legal liabilities and large fixed costs should lie, but it is hard to make these issues go away or become tempting for any private sector owner. Secondly, there is no sign that these assumptions are right in the context of national strategy. This is sad, since the 1993 White Paper Realising Our Potential gave hope that a strategic approach was emerging. Thirdly, there are some very successful partnerships between PSREs, notably with universities, yet also with the industrial sector. These existing networks are endangered. Fourthly, there is little doubt that repeated reviews reduce efficiency and productivity, often with minimal gain. If there is to be disruption of innovation, it needs clearer motivation and exposure to public scrutiny.

How is it that calls for reviews happen so often, when their record is so poor? There are the obvious reasons: review can be politically preferable to action; review can postpone problems until there is a new minister, and so on. But perhaps fashion is more important. The current fashions in the UK are for privatisation and, along with other countries, for networks, which seem to have much to offer without such high direct costs. Perhaps networks do offer real gains. But there is a price to be paid, not least if there is failure to recognise just what the national laboratories have achieved, and especially their contribution to training and to technical infrastructure.

Marshall Stoneham (University College London)

\title{
CECAM
}

\section{Centre Européen de Calcul Atomique et Moléculaire, Lyon, France \\ tel: [+]33-4-7272 8637; fax: [+]33-4-7272 8636; e-mail: cecam @ cecam.fr;www:http://www.cecam.fr]}

\section{Scientific Programme}

- Methods and algorithms for mesoscopic simulation of colloidal particle systems, June 9-12. organized by Joost H.J. van Opheusden and John R. Mehose.

- Enrico Fermi summer school on Computer simulation of rare events and the dynamics of classical and quantum condensed-phase systems, organized by B.J. Berne, G. Cicolti and D. Coker, sponsored by the Italian Physical Society.

- How can ab initio calculations be an effective tool for the study of mineral properties?, June 26-28, organized by Bjoem Winkler and Volker Heine.

- First-principle theory of ferroelectric materials, July 3-5, organized by Raffaele Resta, Xavier Gonze and David Vanderbill.

- Quantum ab-initio simulation of finite temperature electronic systems, July 16-18, organized by Gilles Zerah, Ali Alavi and Bernard Bemu.

- Theoretical and experimental approaches to nucleic acid structure and activity. July 21-23. organized by Lennart Nilsson, B. Montgomery Pettit and Richard Lavery.

- Atoms in strong magnetic fields. August 25-27, organized by Philippe Amault and François Perrot.

- Reactivity at surfaces, August 28-30, organized by Annabella Selloni and Mathias Scheffler.

- Excited electrons in atoms, molecules, and solids, September 8-10, organized by Rex Godby and Barry Pickup.

- Simulation of silicas: from ćlassical pair potentials to density functional theony, September 15-17, organized by Xavier Gonze, Douglas C. Allan and Jean-Christophe Charlier.

- Surfaces and interfaces near equilibrium, September 22-24, organized by David P. Landau.

- The interaction of ultra-intense short pulse laser with plasmas, September 29-October 3. organized by M.G. Haines, G. Bonnaud and A.R. Bell.

- Rheological behavior and structure of confined films. Theoretical approaches and experiments employing the Surface Force Apparatus (SFA), October 14-17, organized by Alain Fuchs and Martin Schoen.

- Ab-initio calculations in relation to modelling mechanical properties of materials, October 20-22, organized by M.W. Finnis and A.E. Carlsson.

- Multi-scale modeling and grand challenge problems in materials research. October 23-25, organized by Efthimios Kaxiras, Sidney Yip, Ulrich W. Suter and Ladislas Kubin.

Scientists wishing to have more information or to participate in one of the above activities are invited to consult our WWW server or to contact the CECAM secretary. Ms. Crespeau, by phone, FAX, or e-mail.

\section{Call for Proposals 1998}

\section{Proposals for the 1998 scientific programme are solicited from the international scientific community}

CECAM meetings typically last from 3 days to 2 weeks. The choice of the format is left to the organizers, but it usually such as to favour individual interactions and an informal atmosphere. Ideally, a CECAM workshop should give rise to one or more new collaborations among the participants.

The scientific programme is decided every year by the CECAM Scientifc Council, which usually gathers in November, upon peer review of proposals. The typical budget allotted to each meeting spans in the 50-100,000 French Francs range, depending on duration and foreseen attendance. Cosponsorships from other agencies are strongly encouraged.

Scientists wishing to submit a proposal should do so preferably by e-mail to the address reported above, or else contact the Director, Stefano Baroni, by e-mail, phone, or FAX. A standard $\mathrm{T}_{\mathrm{E}} \mathrm{Xttemplate}$ for proposals is available from the CECAM WWW server.

The deadline for submitting a proposal is August 31, 1997

CECAM is a consortium of several European national research institutions, aimed at promoting the international cooperation in the fields of Computational Physics and Chemistry. CECAM is presently supported by Belgian FNRS and NFWO, British EPSRC, Dutch NWO. French CEA, CNRS and ENS-Lyon, Greek FORTH, Italian CNR and INFM, and Swiss FNR. 